Printed in Great Britain

\title{
THE DIET AND FEEDING MECHANISM OF IDOTEA
}

\author{
By E. Naylor \\ Marine Biological Station, Port Erin
}

(Text-figs. I and 2)

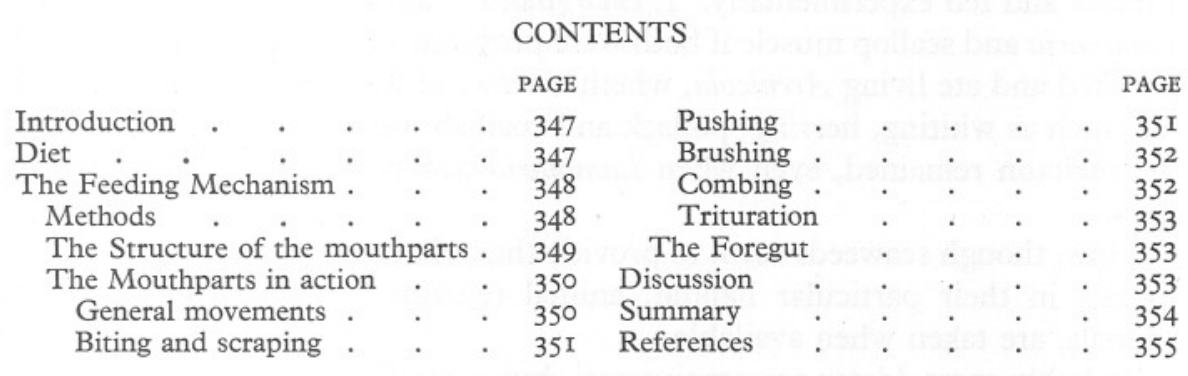

\section{INTRODUCTION}

Few published data are available on the feeding mechanism of isopods; Nicholls (193I) describes the feeding of Ligia oceanica (L.), but he deals mainly with the foregut and the digestive system. The feeding mechanism of the tanaid Apseudes talpa (Montagu) is described by Dennell (1937) but, unlike an isopod, this species still retains a fairly elaborate maxillary filter mechanism. A description of the mode of action of the mouthparts of an isopod such as Idotea is therefore of value for comparison with the general scheme of evolution of peracaridan-feeding mechanisms (Dennell, 1937). In addition, such an account forms a corollary to morphological descriptions of the mouthparts (Naylor, 1955a), and notes on the diet of Idotea supplement observations on the ecology of the various species (Naylor, 1955 b).

\section{DIET}

According to Roux (I829) and Collinge (I9I7), idoteids feed mainly on animal remains, but Bate \& Westwood (I868) maintained that Idotea tricuspidata (now I. baltica (Pallas) and other species) fed on algae. As for the habits of individual species, Dollfus (I895) states that $I$. pelagica Leach is commensal with, or parasitic on, barnacles on the shore, Kjennerud (I952) describes how I. neglecta G. O. Sars eats fish and fish waste in the fish-market harbour at Bergen, and Howes (1939) regards I. viridis (Slabber) from a saline lagoon in Essex as a carnivore feeding chiefly on coelenterates, Membranipora or dead organisms. 
Present observations on the feeding habits of Idotea, when compared with details of the ecological distribution of the species (Naylor, 1955 b), show how each species eats the organisms with which it is associated. Examination of the gut contents shows that most of the food is algal, but some animal remains have been observed, particularly in I. pelagica, which often has barnacle appendages in its gut. In addition, laboratory observations show that an idoteid will eat its own cast skin and other dead Idotea; cannibalism, particularly of moulting individuals, sometimes occurs.

To determine whether plant or animal food is preferred Idotea were kept in aquaria and fed experimentally. I. emarginata (Fabricius) and I. neglecta ate Laminaria and scallop muscle if both were provided as food, and I. emarginata attacked and ate living Arenicola, whether seaweed was present or not. Dead fish such as whiting, herring, pollack and coalfish were eaten till nothing but the skeleton remained, even when Laminaria had been the food for several days.

Thus, though seaweeds seem to provide the bulk of available food for these species in their particular habitat, animal remains, and even some living animals, are taken when available.

Probably most Idotea are omnivorous, but some feeding differences occur depending on the habitat and locality. I. pelagica appears to have similar habits in many localities (Dollfus, I894-5; Sars, I899; Elmhirst, 1946; Kjennerud, I952; Naylor, I955b). The species is found amongst barnacles on exposed shores, but rather than being an ectoparasite of barnacles (Dollfus, I894-5), it seems as though it is a scavenger in its habitat, feeding on cast skins of previously moulted barnacles, as well as on algae. Local differences in diet occur in at least two species. I. neglecta appears to feed largely on decaying weed in Port Erin Bay, yet the species appears to be solely carnivorous in a Norwegian locality (Kjennerud, I952), and I. viridis in the Isle of Man feeds chiefly on algae and not on animal matter as described by Howes (I939). Finally there may also be different food preferences by Idotea of different size; small I. granulosa Rathke, for instance, eat the Cladophora with which they are associated, whilst large specimens eat the fucoids which harbour them (Naylor, 1955b).

\section{The FeEding Mechanism}

\section{Methods}

In favourable conditions, without excess light or heat, Idotea will feed on algae in a Petri dish, and may be examined under a low-power dissecting microscope. In this way, part of the feeding process, particularly the biting and scraping of the weed surface, was observed directly. The remainder of the process of feeding is inferred from the structure and musculature of the mouthparts, and by observing the movements of the mouthparts when the ventral maxillipedes, which cover the other mouthparts, had been removed. 
The removal of the maxillipedes might upset the phase of movement of the mouthparts, but it did not seem to affect the direction of movement of each appendage.

\section{The structure of the mouthparts}

The structure of the mouthparts of Idotea has been described in detail elsewhere (Naylor, I955a), but it is necessary to give a brief summary of that description here so that the mode of action of the mouthparts may be fully understood.

Idoteids have four pairs of oral appendages, namely, mandibles, maxillules, maxillae and maxillipedes, the last of these originating from the thoracic segment incorporated into the cephalon. In addition to these there are the labrum, forming the anterior wall of the oral cavity, and the bilobed paragnath, forming the posterior wall. The mandibles themselves form the lateral walls of the oral cavity. All the paired appendages originate behind the paragnath; they project forwards beneath the head with their tips coming to lie below or just behind the oral cavity (Fig. I).

The labrum is a heavily chitinized structure which is slightly spiny at its lower edge (Fig. I); it abuts against the food mass during feeding.

The mandibles are well developed and are the largest of the oral appendages. Each consists of a ventral incisor process, a lacinia mobilis, a row of toothed spines, and a dorsal molar process (Fig. I), and when the mandibles are closely apposed the structures of the right appendage lie above the corresponding ones of the left side (Fig. 2). In relation to this the two mandibles are structurally asymmetrical; whereas the left lacinia mobilis bears three broad teeth, that of the right mandible has one large spine and several smaller ones and all are less chitinized than those of the left lacinia mobilis. In addition, the molar process of the left mandible is inclined upwards, whilst that of the right side faces somewhat downwards.

The paragnath is bilobed and bears upwardly-directed spines in the midventral groove between the lobes.

Each maxillule has an inner endite bearing three long, and one short, plumose bristles which project between the lobes of the paragnath (Fig. I), and an outer endite bearing a number of stout spines. Each maxilla has a bilobed outer endite bearing comb setae, and an inner endite bearing plumose bristles like those of the maxillule.

The maxillipedes are plate-like and they protect the other mouthparts. They are joined medially by a coupling hook (Fig. I) on each appendage and, unlike the other appendages, the maxillipedes bear palps. The palps are capable of independent lateral movement, and the spines on their inner borders aid in keeping the other mouthparts free of debris.

The first pair of legs on the thorax aid in feeding by holding the food mass and by combing the mouthparts. Unlike the other legs, the dactylopodite is palmate and bears a number of toothed, comb-like spines on its upper surface. 


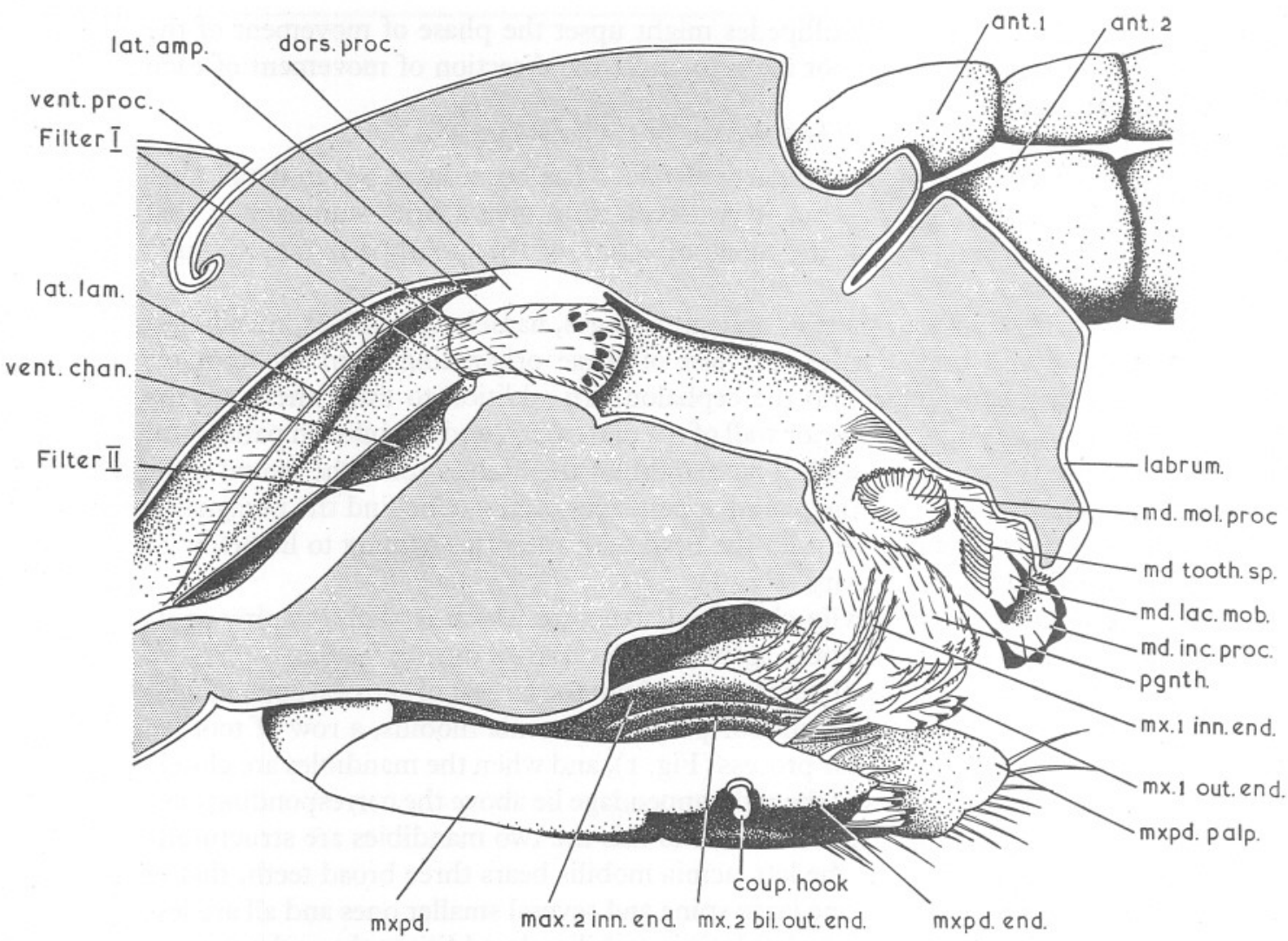

Fig. I. Median view of the left half of the head of I. emarginata, showing the mouthparts and the foregut. Ant. I, first antenna; ant. 2, second antenna; coup. hook, coupling hook on maxillipede; dors. proc., dorsal process; lat.amp., lateral ampulla; lat. lam., lateral lamella; md.inc.proc., incisor process of mandible; md.lac.mob., lacinia mobilis of mandible; md.mol.proc., molar process of mandible; md.tooth.sp., toothed spines of mandible; $m x$. I inn. end., inner endite of maxillule; $m x$. I out. end., outer endite of maxillule; $m x .2$ bil. out.end., bilobed outer endite of maxilla; $m x$. 2 inn.end., inner endite of maxilla; $m x p d$., base of maxillipede; $m x p d$. end., endite of maxillipede; $m \times p d$. palp, palp of maxillipede; pgnth., paragnath; vent.chan., ventral channel; vent.proc., ventral process.

\section{General Movements}

\section{The Mouthparts in action}

During feeding the mandibles bite sideways. The maxillules move obliquely forwards till they meet in the mid-line and then they may or may not move forwards together. It is important to note that the mandibles and maxillules alternate in their movements.

The maxillae move in a manner similar to that of the maxillules, converging anteriorly to about the same level as the posterior limit of the tips of the maxillules. The maxillipedes, being coupled together medially, move forwards and backwards, with no lateral movement except in the palps. 
All these movements may vary according to whether the animal is actually biting the food material or only clearing the mouthparts of debris collected there.

\section{Biting and Scraping}

From a functional point of view all the mouthparts but the maxillae are built on a similar plan. Ventrally placed on each appendage are heavily chitinized structures for biting or scraping the food material. There are broad, scleratized teeth on the incisor process of each mandible, and on the lacinia mobilis of the left appendage. The outer endite of the maxillule has four, heavily chitinized, chisel-shaped spines ventral to the other spines, and the maxillipedes have five or six scraping spines situated ventrally on their inner parts.

When the animal is feeding, the maxillules come together as the mandibles separate, and in doing so they abrade the edge of the weed and facilitate the work of the mandibles when these next bite. To a certain extent the spines on the maxillipedes probably also help in abrading the weed, but this pair of appendages, like the maxillules, do not bite the food material.

The maxillae take no part in abrading or biting the weed; they are hardly scleratized at all.

\section{Pushing}

Above the biting and scraping parts of the appendages are structures concerned with the removal of food from the biting parts and with its transfer to the molar processes for chewing. Serving to transfer food upwards along the mandibles are the row of toothed spines and the lacinia mobilis of each side (Fig. 2). By their very arrangement these should push food upwards every time the mandibles come together. Cannon \& Manton (1927, p. 235), in describing the asymmetrical arrangement of the mandibles in Hemimysis, state that it provides 'a mechanism by which simple lateral movements of the mandibles must transfer food from the ventral incisor processes to the dorsal molar processes'.

In addition to those on the mandibles there are toothed spines on the maxillules. These lie dorsal to the four scraping spines (Fig. I) and they point upwards and inwards between the paragnaths; they must aid in pushing the bitten food mass upwards. Here again it is important that the mandibles and maxillules alternate in their movements. At the time when the food bitten by the mandibles is likely to fall between them as they retract, the maxillules are coming together; in doing so they will push inwards any food which is likely to fall, and the toothed nature of the spines should make them more efficient in this respect. 


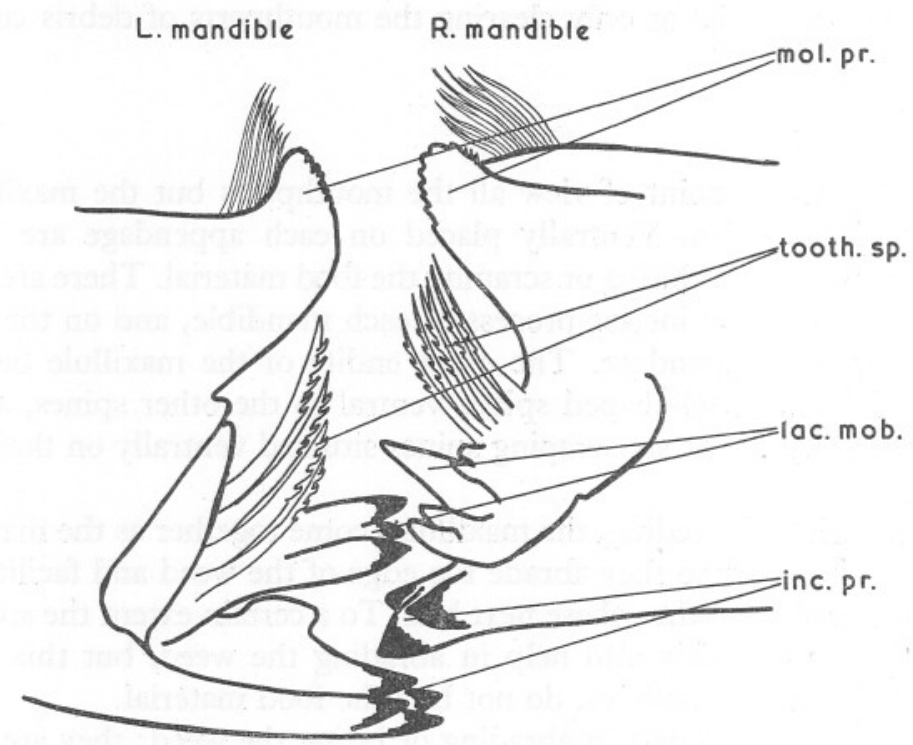

Fig. 2. The apposed mandibles, seen from behind (mol.pr., molar process; tooth.sp., toothed spines; lac.mob., lacinia mobilis; inc.pr., incisor process).

\section{Brushing}

Escaping particles of food are probably dealt with by the plumose, or brush setae, on the maxillules, maxillae and maxillipedes. It is difficult to observe these setae in action but, from the general movement of the appendages, some idea of their function may be inferred.

The plumose setae move mainly forwards and backwards, since they are on the inner parts of the appendages, and the setae of each member of the pair of appendages meet in the mid-ventral line. The three pairs of appendages normally move out of phase with each other, and particles of food are probably brushed forwards from one to the other until they are combed off the setae of the maxillules by the spines on the paragnath.

From there the food particles will be pushed between the mandibles by the toothed spines on the outer endite of the maxillule, and by the brush setae on the inner endite of that appendage. Once between the mandibles, as described earlier, food passes up to the molar processes by virtue of lateral movements of the mandibles themselves.

\section{Combing}

It is necessary in such a method of feeding, where small particles of food will tend to cling to various appendages, for there to be combing mechanisms to remove such debris. Comb spines on the first pair of legs and the long 
smooth spines on the inner border of the maxillipedal palp, have already been described as aiding in keeping the mouthparts free of debris. In addition, short smooth spines on the paragnath have been mentioned as combing food particles from the brush setae of the inner endites of the last three pairs of mouthparts. Other structures which probably aid in combing the mouthparts are the spines on the outer endites of the maxillae (Fig. I), and the two flexible, blade-like structures, fringed with stiff bristles, which are situated ventrally on the tips of the maxillules (Naylor, I955a).

\section{Trituration}

All the movements of the mouthparts serve to push the food forwards and upwards to the molar processes of the mandibles. These have blade-like ridges on their apposing surfaces, which slide across each other to crush the food. From there the triturated food passes to the fore-gut.

\section{The Foregut}

The foregut of Idotea is very similar to that described for Asellus (Rehorst, I9I4) and for Ligia (Nicholls, I93I). The latter author reviews much literature on the foregut of isopods, and the terminology adopted by him is used here.

Anteriorly, on each side-wall of the foregut, arise the paired, lateral ampullae. These appear to crush the food material so that fluid is sifted from the solid matter through paired, ventral bristle-plates, which open into a midventral channel (filter I). The channel is formed by the anterior ventral lamellae, and it is divided medially, at its posterior end, by a second filter apparatus (filter II). On either side of this structure, running parallel with its upper edge, lies a groove covered with strong bristles. The grooves are blind anteriorly, but posteriorly they open into the three digestive caeca of each side; fluid passes between the setae and into the caeca. A backward projection of the second filter apparatus acts as a valve over the opening from the caeca into the intestine.

Solid food is prevented from being regurgitated by a series of membranous flaps in the foregut, namely, the paired lateral lamellae, the dorsal lamella, the paired, posterior ventral lamellae, and the ventral valve. All except the lateral lamellae arise at the posterior end of the foregut and project into the intestine.

\section{Discussion}

From what has been said of the diet and action of the mouthparts, it is clear that Idotea must feed on large food masses; it cannot filter food from suspension, and in this respect it is a typical 'higher' peracaridan (Dennell, I937). The general method of feeding of Idotea, whereby the animal browses on its 
food, scraping and biting pieces from it, is similar to that described for Ligia (Nicholls, I931).

The 'higher' Peracarida, which feed on large food masses, are thought to have been derived from an entirely filter-feeding ancestor (Cannon \& Manton, 1927; Manton, 1928; Dennell, 1937), and the first adoption of the bottomliving habit by a peracaridan with an elaborate maxillary filter may have been the result of seeking larger food particles from the bottom (Manton, I928). The first stage in obtaining larger food appears to have been the direct intake of fairly large particles by the mandibles, the outer endites of the maxillules, and possibly other appendages as well; this has been observed in Hemimysis (Cannon \& Manton, 1927), and in Apseudes (Dennell, 1937). It is then an easy step towards the elaboration of the mandibles and the outer endites of the maxillules, so as to bite into, and break pieces from, more solid food.

As the filter-feeding mechanism has become of less importance in the 'higher' Peracarida, the inner endite of the maxillule, and the whole of the maxilla, have become reduced, and the mouthparts have become covered ventrally by the plate-like maxillipedes. All these changes appear to have taken place with the loss of the ventral food current, and they have occurred in the evolution of the Isopoda.

In Idotea the equivalent of the filtering mechanism, namely the inner parts of the hinder three pairs of mouthparts, apparently serves to brush into the mouth particles of food which escape from the biting parts of the appendages. The mouthparts are very compact, but the feeding mechanism is still elaborate, particularly when the division of labour between the various parts of each appendage is considered.

With the adoption of a bottom-living habit and a raptatory mode of feeding, characteristic of the 'higher' Peracarida, and with its generalized food requirements (p. 348), Idotea is well suited to occupy a wide range of habitat.

\section{SUMMARY}

Idotea feeds on large food masses. It is potentially an omnivorous scavenger, but each species may have a characteristic diet depending on the availability of food in its particular habitat.

The structure, topography and action of the mouthparts are described: spines on the maxillules and maxillipedes scrape the food material whilst the mandibles actually bite the food; toothed spines on the maxillules and mandibles push the food upwards to the molar processes of the mandibles; debris is brushed forwards between the lobes of the paragnath by setae on the inner endites of the maxillules, maxillae and maxillipedes; and spines on the maxillipedal palp, and on the first leg, comb the mouthparts.

The structure of the foregut resembles that of Asellus and Ligia.

The relation of the feeding mechanism to the functional evolution of the mouthparts of Peracarida as a whole is discussed. 


\section{REFERENCES}

BAte, C. S. \& Westwood, J. O., I868. A History of the British Sessile-Eyed Crustacea, Vol. 2, 536 pp. London: van Voorst.

Cannon, H. G. \& Manton, S. M., I927. On the feeding mechanism of a mysid crustacean, Hemimysis lamornae. Trans. roy. Soc. Edinb., Vol. 55, pp. 219-54.

Collinge, W. E., I9I7. A revision of the British Idoteidae, a family of marine Isopoda. Trans. roy. Soc. Edinb., Vol. 51, pp. 72I-60.

DenNell, R., I937. On the feeding mechanisms of Apseudes talpa, and the evolution of the peracaridan feeding mechanisms. Trans. roy. Soc. Edinb., Vol. 59, pp. $57-78$.

Dollfus, A., I894-5. Les Idoteidae des côtes de France. Feuill. jeun. Nat., 25e Année, pp. I-5, I7-18, 38-40, 53-6.

Elmhirst, R., I946. Notes on Idotea spp. Scot. Mar. biol. Ann. Rep., I942-43, p. I2.

Howes, N. H., I939. Observations on the biology and post-embryonic development of Idotea viridis (Slabber) (Isopoda, Valvifera) from New England Creek, southeast Essex. F. Mar. biol. Ass. U.K., Vol. 23, pp. 279-310.

KJENNERUD, J., 1952. Ecological observations on Idothea neglecta G. O. Sars. Univ. Bergen Arbnaturv., I950, Nr. 7, 47 pp.

Manton, S. M., I928. On some points in the anatomy and habits of the lophogastrid Crustacea. Trans. roy. Soc. Edinb., Vol. 56, pp. I03-I9.

NAYLOR, E., I955a. The comparative morphology and revised taxonomy of British Idotea. F. Mar. biol. Ass. U.K. (In the Press.)

- I I 955 b. The ecological distribution of British species of Idotea. F. anim. Ecol. (In the Press.)

Nicholls, A. G., I93I. Studies on Ligia oceanica. Parts I and II. F. Mar. biol. Ass. U.K., Vol. I7, pp. 655-73, 675-707.

Rehorst, G., I9I4. Der Filtermagen von Asellus aquaticus. Zool. Anz. Bd. 44, pp. 228-34.

Roux, J. L. F. P., I829. Crustacées de la Méditerranée et de son littoral, décrits et lithographiés. Marseilles.

SARS, G. O., I899. Isopoda. Crustacea of Norway, Vol. 2, 270 pp. Bergen: Bergen Museum. 